\title{
Feedbacks of biotically induced radiative heating on upper-ocean heat budget, circulation, and biological production in a coupled ecosystem-circulation model
}

\author{
Andreas Oschlies ${ }^{1}$ \\ Leibniz-Institut für Meereswissenschaften an der Universität Kiel, Kiel, Germany \\ Received 13 April 2004; revised 13 August 2004; accepted 10 November 2004; published 28 December 2004.
}

[1] A coupled ecosystem-circulation model of the North Atlantic Ocean is used to investigate the impact of radiative heating by biotically induced absorption of solar radiation on the ocean's heat budget, on water column stability and circulation, and on biological production itself. For fixed atmospheric conditions, the local sensitivity of the nonsolar heat flux to changes in sea surface temperature leads to a net cooling of the ocean by the biota at a rate of about $1 \mathrm{~W} \mathrm{~m}^{-2}$. As a result, simulated winter mixed-layer depths are deeper by more than $100 \mathrm{~m}$ in parts of the subpolar gyre, whereas upper-ocean stratification is enhanced in the tropics and subtropics, and coastal upwelling and associated nutrient supply are reduced by about $10 \%$ compared to a model run with optical properties of clear seawater. Simulated chlorophyll concentrations increase, indicating a positive feedback, only in subpolar regions that exhibit a pronounced phytoplankton spring bloom. Here biotically induced trapping of heat closer to the sea surface leads to a faster shoaling of the mixed layer and a more intense spring bloom in the model. On the basin average, simulated surface chlorophyll concentrations, however, decrease by $3 \%$, constituting a weak negative feedback of $0.03 \mathrm{~W} \mathrm{~m}^{-2}$, when heating by biotic absorption of solar radiation is accounted for. These findings are based on the approximation of the atmosphere as a passive heat buffer and will have to be tested against results from fully coupled atmosphere-ocean models with interactive marine biology. INDEX TERMS: 1635 Global Change: Oceans (4203); 4255 Oceanography: General: Numerical modeling; 4504 Oceanography: Physical: Air/sea interactions (0312); 4552 Oceanography: Physical: Ocean optics; 4572 Oceanography: Physical: Upper ocean processes; KEYWORDS: attenuation, chlorophyll, radiative heating

Citation: Oschlies, A. (2004), Feedbacks of biotically induced radiative heating on upper-ocean heat budget, circulation, and biological production in a coupled ecosystem-circulation model, J. Geophys. Res., 109, C12031, doi:10.1029/2004JC002430.

\section{Introduction}

[2] In the open ocean, photosynthetic chlorophyll-like pigments of phytoplankton are the dominant variable control on the scattering and absorption of short-wavelength solar radiation incident on the ocean surface [e.g., Morel and Antoine, 1994]. By changing the optical properties of the surface waters, marine biota can alter both the total amount of solar radiation that enters the ocean and the vertical profile of its absorption. The former process is associated with biotically induced changes in the albedo, i.e., the ratio of upward to downward short-wavelength radiation right above the sea surface. The latter process describes the biotically induced conversion of short-wavelength solar radiation into heat (and of a very small fraction into internal energy of photosynthetically generated organic compounds). Biotically induced increases in the albedo, most prominently by

\footnotetext{
${ }^{1}$ Now at Southampton Oceanography Centre, Southampton, UK.
}

calcium carbonate shells of coccolithophores, has been estimated to result in a net global cooling of the ocean by about $0.2 \mathrm{~W} \mathrm{~m}^{-2}$ [Tyrrell et al., 1999]. To my knowledge, a similar quantitative estimate has not yet been performed for the sensitivity of the net air-sea flux to biotically induced changes in the absorption profile in the water.

[3] Initial studies of the impact of biotically effected absorption of solar radiation on the physical state of the upper ocean were based on one-dimensional models of the upper ocean that were driven by prescribed solar and nonsolar heat fluxes. Simpson and Dickey [1981] investigated several idealized forcing scenarios and inferred additional surface-layer heating of up to $1^{\circ} \mathrm{C}$ per day in low-wind conditions and for typical oceanic pigment concentrations. In a similar setup with realistic atmospheric forcing for Stations N and P in the North Pacific, Martin [1985] reported simulated summer sea surface temperatures (SSTs) being warmer by several degrees when optical properties were changed from those of clear seawater to those of a relatively dense algal bloom. Applying a coupled biological-physical model of the water column to a site in the spring-bloom region of the eastern North Atlantic, Simonot et al. [1988] 
found a biotically induced SST increase by up to $2{ }^{\circ} \mathrm{C}$ during spring and summer. Similarly large seasonal heating rates have been inferred from an analysis of satellite ocean color data for the Arabian Sea [Sathyendranath et al., 1991].

[4] All of the above early studies assumed fixed surface fluxes of heat and momentum that could not react to the biotically induced changes in SSTs. Under this assumption, only the vertical heating profile in the upper ocean $(<200 \mathrm{~m})$ is affected by the presence of phytoplankton, but the total oceanic heat content is not. That is, heating of the surface layers is exactly balanced by cooling of the layers beneath.

[5] The present paper will follow more recent model studies [Rochford et al., 2001; Murtugudde et al., 2002] and go beyond the assumption of fixed surface heat fluxes. Since elevated SSTs will tend to increase oceanic heat loss by evaporation, long-wavelength radiation, and sensible heat fluxes, this results in a negative feedback on the SST. As the incoming solar radiation does not directly depend on SST (it may be influenced indirectly via changes in cloudiness), the net effect of trapping solar radiation closer to the sea surface is a net cooling of the ocean. Although previous studies have implicitly accounted for a possible feedback of SST on nonsolar components of the heat flux [Rochford et al., 2001; Murtugudde et al., 2002], they did not report on the consequences for the net heat budget of the ocean. More importantly, none of these studies used an interactive biological model that is needed to account for possible feedbacks on the biota itself. This feedback may be positive because of increased light levels experienced by the phytoplankton in the more stably stratified surface layer, as suggested by Sathyendranath et al. [1991] for the Arabian Sea, or may be negative because of reduced nutrient supply from below.

[6] In an attempt to quantify the impact of the marine pelagic biota on the upper-ocean heat budget, on stratification and circulation, and also on nutrient supply, primary production, and the resulting chlorophyll concentration itself, a reasonably realistic ecosystem-circulation model of the North Atlantic is employed in this study. After a brief description of the numerical model in the following section, biotically effected changes in the surface heat budget are examined in section 3. Impacts on net air-sea heat fluxes and winter mixed-layer depths as well as feedbacks on circulation, nutrient supply, primary production, and chlorophyll concentrations are discussed in section 4 . Conclusions are presented in section 5 .

\section{Numerical Model}

[7] The numerical model consists of a simple nitrogenbased four-compartment ecosystem model [Oschlies and Garçon, 1999] coupled to an eddy-permitting $z$-level circulation model based on the Geophysical Fluid Dynamics Laboratory's (GFDL) Modular Ocean Model (MOM [Pacanowski et al., 1991]) code. It covers the North Atlantic between $15^{\circ} \mathrm{S}$ and $65^{\circ} \mathrm{N}$ at a resolution of $1 / 3$ times $2 / 5$ degrees in meridional and zonal direction, respectively. The model grid resolves 37 vertical levels with 11 levels in the uppermost $150 \mathrm{~m}$. The thickness of the topmost layer is $11 \mathrm{~m}$. Vertical mixing is modeled by a turbulent kinetic energy (TKE) closure scheme [Gaspar et al., 1990] tuned to closely match observational estimates of diapycnal diffusion derived from a tracer-release experiment in the main thermocline of the eastern subtropical North Atlantic [Ledwell et al., 1993, 1998]. Well below the surface mixed layer, diffusivities $K_{\rho}$ are approximately proportional to the inverse of the stability frequency $N$ and approach the relation $K_{\rho}=a N^{-1}$ with $a=5.7 \times 10^{-4} \mathrm{~cm}^{2} \mathrm{~s}^{-2}$.

[8] The model is forced by monthly mean wind stress and heat flux fields derived from the years 1989 to 1993 of the reanalysis project carried out at the European Centre for Medium-Range Weather Forecasts (ECMWF) [Gibson et al., 1997]. The formulation of the surface heat flux follows Haney [1971], with the downward heat flux into the ocean expressed as

$Q_{\mathrm{NET}}\left(\mathrm{SST}_{\mathrm{mod}}\right)=Q_{\mathrm{SOL}}+Q_{\mathrm{NSOL}}\left(\mathrm{SST}_{\mathrm{obs}}\right)+Q_{2}\left(\mathrm{SST}_{\mathrm{mod}}-\mathrm{SST}_{\mathrm{obs}}\right)$

with

$$
Q_{2}=\left(\frac{\partial Q_{\mathrm{NSOL}}}{\partial \mathrm{SST}}\right)_{\mathrm{SST}_{\mathrm{obs}}} .
$$

$Q_{\mathrm{SOL}}$ and $Q_{\mathrm{NSOL}}$ account for solar and nonsolar heat fluxes as provided by the ECMWF reanalysis. $\mathrm{SST}_{\mathrm{obs}}$ is the observed weekly sea surface temperature field [Reynolds and Smith, 1994] that was also used in the ECMWF reanalysis. $Q_{2}$ represents the change of the surface heat flux per degree Celsius deviation of the simulated SST from the observed one. It has been computed from the 6-hourly reanalysis fields by a linear expansion of the surface heat flux bulk formulae [Barnier et al., 1995]. The $Q_{2}$ term in (1) thus represents a physically plausible flux correction that accounts for a local feedback of the simulated SST on the heat flux felt by the model ocean. Note, however, that this linearization neglects any SST-driven changes in atmospheric circulation or boundary layer properties, and approximates the atmospheric response as that of a passive (and infinite) heat buffer. The experiments described in this study use a "climatologically" averaged $Q_{2}$ that was computed over the 5-year period 1989 to 1993 and varies in space but not in time. Typical values for $Q_{2}$ are in the range of 30 to $45 \mathrm{~W} \mathrm{~m}^{-2} \mathrm{~K}^{-1}$ [see Oschlies, 2002, Figure 9]. Because precipitation fields were considered to be not yet reliable enough, freshwater fluxes were parameterized by restoring surface salinity to observed monthly means taken from the Levitus et al. [1994] atlas.

[9] It can safely be assumed that all nonvisible longwavelength $(\lambda>700 \mathrm{~nm})$ solar radiation is always absorbed in the uppermost grid box $\left(\Delta z_{1}=11 \mathrm{~m}\right)$ and that only the short-wavelength visible radiation can penetrate to deeper layers [e.g., Morel and Antoine, 1994]. This portion is roughly identical to that of the photosynthetically active radiation (PAR) and was taken to make up for $43 \%$ of the solar energy flux at the sea surface [Jerlov, 1976]. The vertical profile of PAR was computed as by Oschlies and Garçon [1999] via

$$
I(z, t)=I(t)_{z=0} e^{\left(k_{w} \tilde{z}-\int_{\tilde{z}}^{0} k_{c} \mathrm{P} d z\right)},
$$

where $\tilde{z}=z / \sqrt{1-(\cos \theta / 1.33)^{2}}$ is the effective length of the radiation path with incidence angle $\theta$ at noon, $k_{w}=$ 


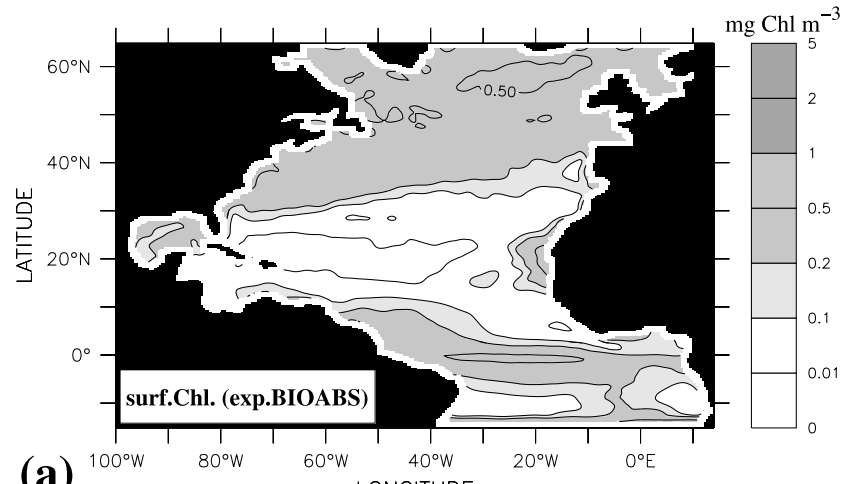

(a)

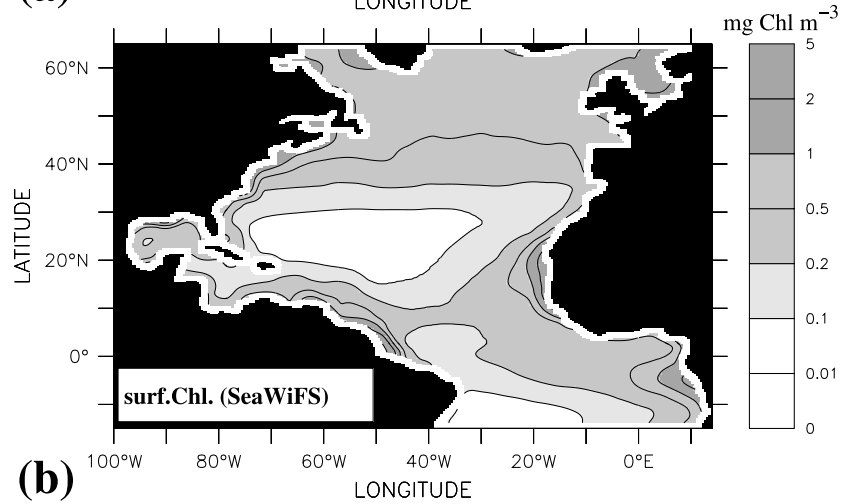

Figure 1. (a) Annually averaged simulated surface chlorophyll in $\mathrm{mg} \mathrm{Chl} \mathrm{m}{ }^{-3}$ computed from the model phytoplankton via a constant ratio of $1.59 \mathrm{~g}$ chlorophyll per mol nitrogen. (b) Mean chlorophyll concentrations derived from SeaWiFS data over the period 1998-2002.

$0.04 \mathrm{~m}^{-1}$ is the light attenuation due to clear seawater, and $k_{c}$ is the light attenuation due to phytoplankton (P) measured in mmol $\mathrm{N} \mathrm{m}^{-3}$. The vertical derivative of $I(z, t)$ then gives the absorption profile of the short-wave portion of the solar radiation spectrum. The phytoplankton concentration is computed at each model time step by the ecological model presented in detail by Oschlies and Garçon [1999]. An evaluation of the model performance is provided by Oschlies et al. [2000], and Figure 1 shows the relatively good agreement between simulated and satellitederived surface chlorophyll (employing a constant chlorophyll-to-nitrogen ratio of $1.59 \mathrm{mg} \mathrm{Chl}(\mathrm{mmol} \mathrm{N})^{-1}$ to convert simulated phytoplankton to chlorophyll).

[10] For the computation of the depth-dependent photosynthesis rate, the value $\left.k_{c}=0.03 \mathrm{~m}^{-1}(\mathrm{mmol} \mathrm{N} \mathrm{m})^{-3}\right)^{-1}$ was used as by Oschlies and Garçon [1999]. If a fixed chlorophyll-to-nitrogen ratio of $1.59 \mathrm{mg} \mathrm{Chl}(\mathrm{mmol} \mathrm{N})^{-1}$ is assumed, this value of $k_{c}$ turns out to be too low when compared to observations of chlorophyll-dependent attenuation [e.g., Morel, 1988]. In order to achieve a better agreement with observational data, a value of $k_{c}=$ $\left.0.075 \mathrm{~m}^{-1}(\mathrm{mmol} \mathrm{N} \mathrm{m})^{-3}\right)^{-1}$ was employed in the heat equation. This pragmatic choice yields attenuation lengths very close to those corresponding to an observational fit by Morel [1988] used in some previous model studies [Murtugudde et al., 2002], as illustrated for the satellitederived chlorophyll field in Figure 2. This ensures that the simulated biotically induced heating profiles are in the same range as those occurring in reality.
[11] Employing a larger attenuation coefficient in the heat equation than in the photosynthesis equation can be thought of as partial compensation for the ecosystem model's neglect of a variable chlorophyll-to-nitrogen ratio and of phytoplankton acclimation. Observed chlorophyll-to-nitrogen ratios tend to be higher at darker deeper levels and lower close to the sea surface, giving phytoplankton some flexibility to acclimate to different light environments [Geider et al., 1996]. As a result, phytoplankton growth occurs on average deeper in the water column than would the growth of a "model phytoplankton" with a constant chlorophyll-tonitrogen ratio (with the constant ratio fixed at the vertical average of the variable ratio). A similar effect is obtained here by using a smaller attenuation coefficient in the chlorophyll equation. Admittedly, this is a crude approximation, and more refined models, which will probably have to include multiple optical wavelength bands and variable chlorophyll-to-nitrogen ratios as a function not only of light but also of nutrients and temperature [Geider et al., 1998], will be required to achieve a better quantitative agreement with observed photosynthesis rates and heating rates at the same time.

[12] In the standard experiment, named BIOABS, solar radiation is absorbed by both clear water and phytoplankton as described above. In a reference experiment, named PHYSABS, solar radiation is, in the heat equation, absorbed only by clear ocean water without being influenced by the presence of phytoplankton. Note that biotic absorption is taken into account in the photosynthesis equation of both experiments in exactly the same way. Absorption of solar radiation is treated differently only in the heat equation. Both simulations were started from a 25-year spinup of the physical model in PHYSABS mode. After the biological model and the respective absorption law were coupled in, an approximately stable seasonal cycle of upper ocean proper-

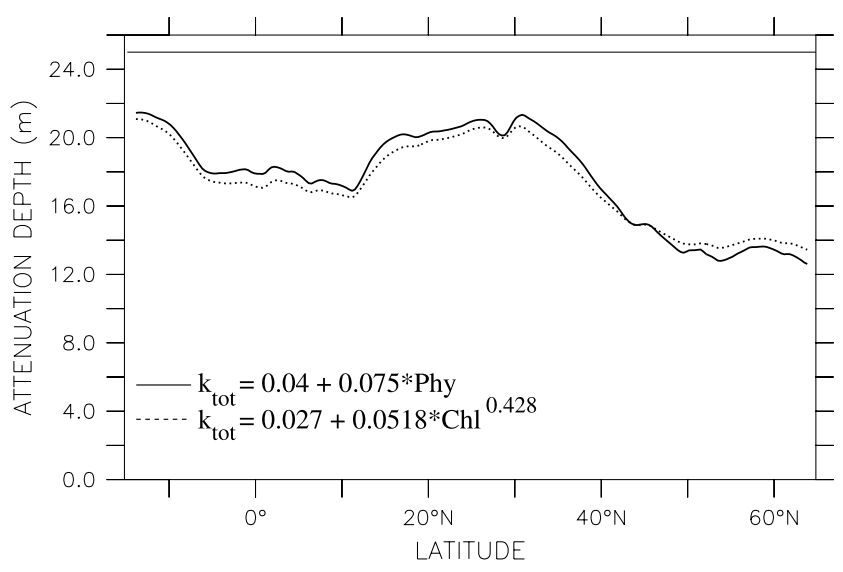

Figure 2. Zonally averaged attenuation lengths computed for surface waters with the satellite-derived chlorophyll field of Figure $1 \mathrm{~b}$. The solid line refers to an attenuation given by $k_{\text {tot }}=0.04+0.075$ Phy with $k_{\text {tot }}$ in $\mathrm{m}^{-1}$ and Phy in mmol $\mathrm{N} \mathrm{m}^{-3}$ as used in experiment BIOABS. The dashed line refers to the formula $k_{\text {tot }}=0.027+$ $0.0518 \mathrm{Chl}^{0.428}$, with $\mathrm{Chl}$ in $\mathrm{mg} \mathrm{m}^{-3}$, suggested by Morel [1988]. The horizontal solid line just below the top of the plot refers to the constant clear-water attenuation coefficient used in experiment PHYSABS. 


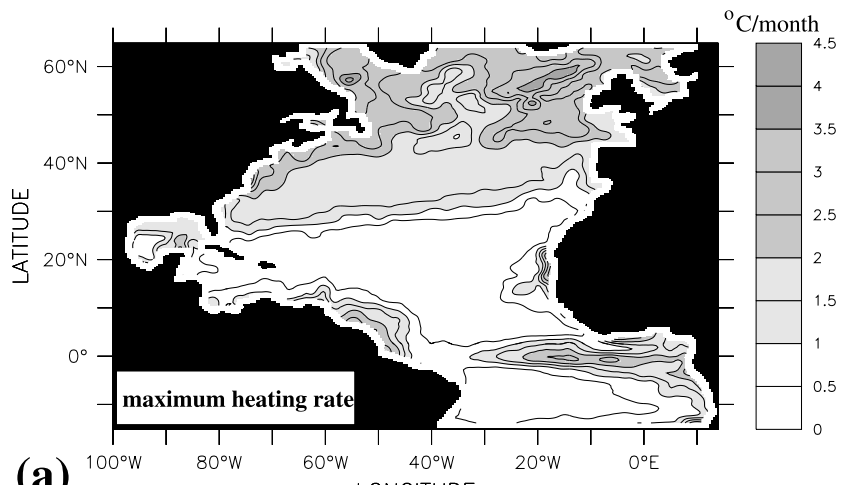

(a)

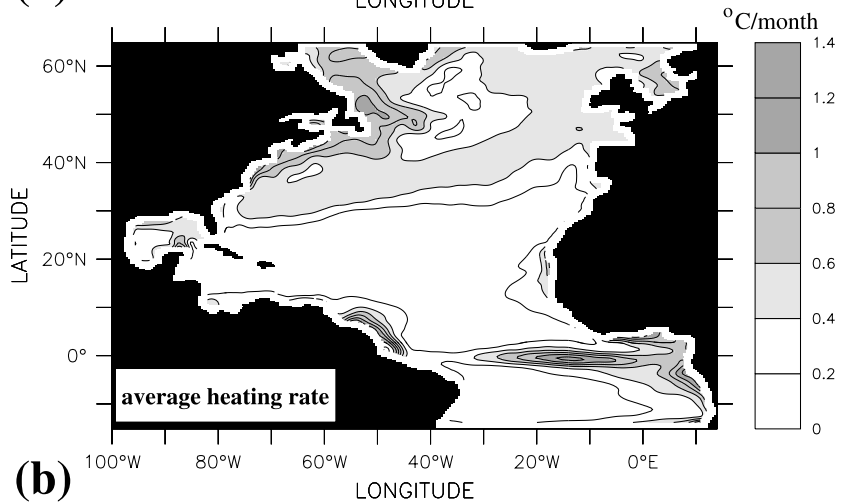

Figure 3. (a) Maximum radiative mixed-layer heating rates reached at each location during the annual cycle in experiment BIOABS. (b) Simulated annually averaged radiative mixed-layer heating rates.

ties was reached for both simulations within 2 years. The results shown below always represent 5 -year averages over the coupled years 3 to 7 .

\section{Impact on Surface Heat Budget}

\subsection{Biotically Induced Radiative Heating of the} Mixed Layer

[13] A simple example illustrates the magnitude of biotically induced absorption of short-wave radiation and its subsequent transformation into heat: Consider a homogeneous chlorophyll concentration of $3 \mathrm{mg} \mathrm{m}^{-3}$, which is a concentration typical for midlatitude open-ocean phytoplankton blooms. For a typical 24-hour-average solar radiation of $200 \mathrm{~W} \mathrm{~m}^{-2}$ at the sea surface, of which $43 \%$ are assumed to be in the visible range [Jerlov, 1976], this reduces the penetrative solar-radiation flux at a depth of $20 \mathrm{~m}$ by some $35 \mathrm{~W} \mathrm{~m}^{-2}$ compared to the clear seawater case. If the upper $20 \mathrm{~m}$ were well mixed, this would generate an additional warming of $1.1^{\circ} \mathrm{C}$ per month. In general, the biotically effected radiative heating of the surface mixed layer will depend on both chlorophyll concentration and mixed-layer depth.

[14] Simulated radiative heating rates that arise from the biotically induced absorption of solar radiation within the surface mixed layer reach maximum values of $4^{\circ} \mathrm{C} /$ month in early summer in the subpolar North Atlantic (Figure 3). These values are computed from the simulated chlorophyll concentrations in experiment BIOABS and do not take into account possible biotically induced changes in mixed-layer depth, nutrient supply, or phytoplankton concentrations (to be considered in the subsequent sections). Similar values were derived by Sathyendranath et al. [1991], who applied a similar method to observations in the Arabian Sea. On the annual average, radiative mixed-layer heating rates simulated for the North Atlantic are always smaller than $1.4^{\circ} \mathrm{C} /$ month, with highest values in the subpolar North Atlantic where pronounced spring blooms occur in very shallow mixed layers, and in tropical and subtropical upwelling regions where chlorophyll concentrations are somewhat lower but more persistent throughout the annual cycle.

[15] To the extent that the biota change the absorption profile but not the total amount of solar radiation absorbed, any extra heating near the surface must exactly be compensated by an extra cooling farther down in the water column. Hence the vertical integral of the immediate radiative heating that arises from biotically induced changes in the absorption profile is always zero. Were it not for feedback mechanisms involving nonsolar surface heat fluxes, the absorption of solar radiation by phytoplankton would have no effect on the total heat content of the ocean.

\subsection{Feedback of Nonsolar Surface Heat Fluxes: Atmosphere as Passive Heat Buffer}

[16] Despite the above-mentioned relatively high biotically induced radiative heating rates, SSTs cease to increase
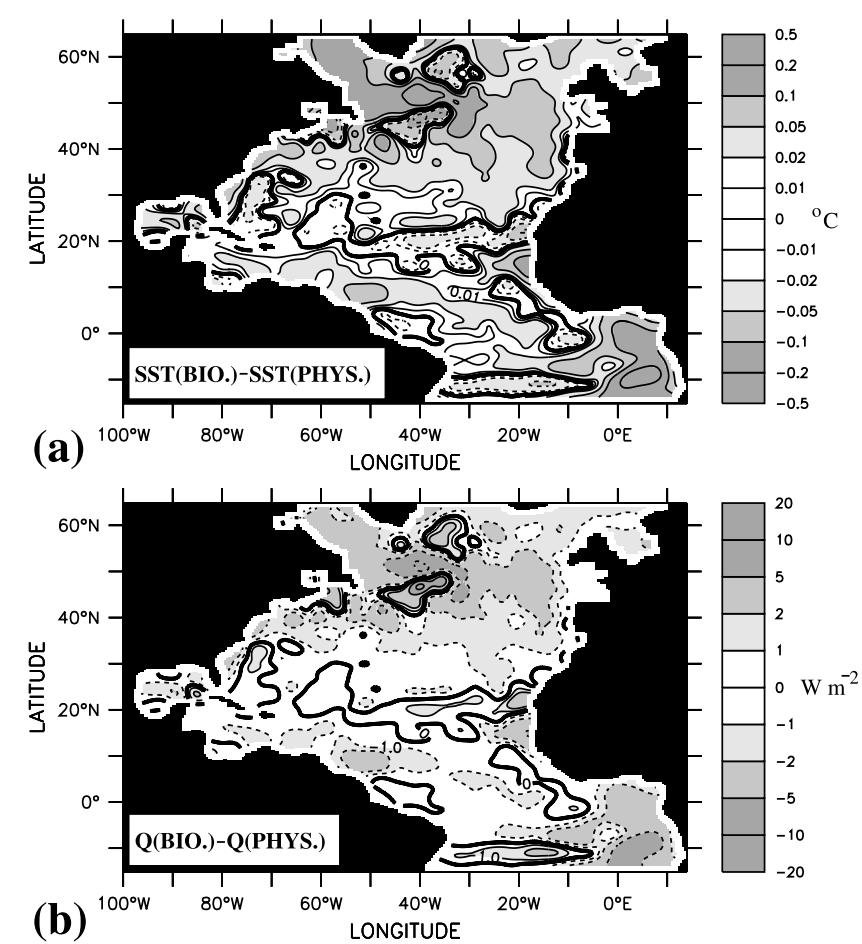

Figure 4. (a) Five-year average of sea surface temperature difference in degrees Celsius of experiment BIOABS (which includes absorption by chlorophyll in the heat equation) minus experiment PHYSABS (which does not include absorption by chlorophyll in the heat equation). (b) Five-year average of surface heat flux in $\mathrm{W} \mathrm{m}^{-2}$ of experiment BIOABS minus experiment PHYSABS. The thick line is the zero contour, and dashed lines refer to negative values. 


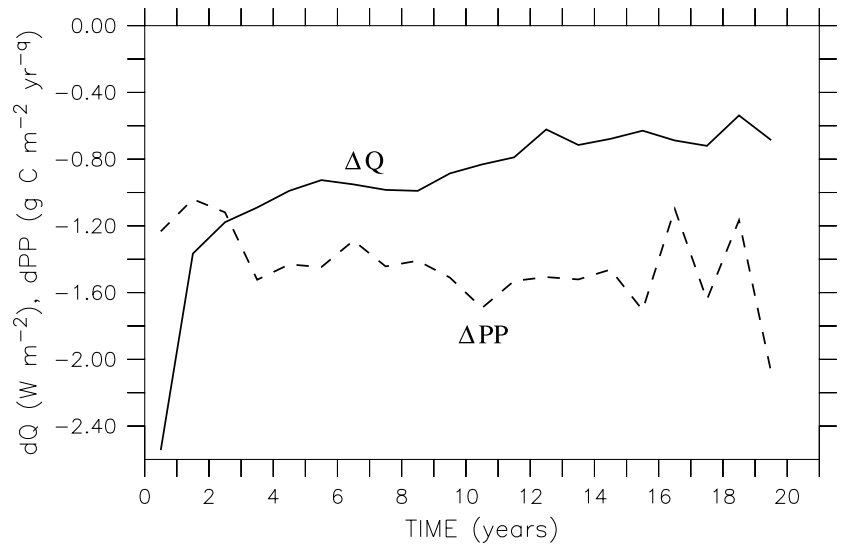

Figure 5. Evolution of the difference in simulated air-sea heat flux (solid line) and primary production (dashed line) of experiment BIOABS minus experiment PHYSABS for the first 20 years after putting in the biology in run BIOABS.

already within a few months after biotic absorption of solar radiation has been switched on in the model. In fact, simulated SSTs in experiment BIOABS are only a few hundredths of a degree higher (on average by $0.03^{\circ} \mathrm{C}$ ) than in run PHYSABS (Figure 4a). Nonsolar sea-air heat fluxes, namely evaporation, sensible heat flux, and long-wavelength radiation, all increase with increasing SSTs and thereby exhibit a negative feedback on changes in SST. In the model, the dependence of the nonsolar heat fluxes on SST is computed by linear expansion of the bulk formulae about the observed local SST (see section 2). This linearization neglects any SST-driven changes in atmospheric conditions and approximates the atmospheric response as that of a passive heat buffer.

[17] Within this local approximation, simulated air-sea heat fluxes turn out to be smaller by more than $5 \mathrm{~W} \mathrm{~m}^{-2}$ in parts of the subpolar gyre and in the coastal upwelling regions off West Africa (Figure 4b). These regions also exhibit the largest SST increase of $0.1-0.2^{\circ} \mathrm{C}$. On average, total air-sea heat fluxes are smaller by $1.0 \mathrm{~W} \mathrm{~m}^{-2}$ in experiment BIOABS compared to experiment PHYSABS. That is, the presence of upper-ocean biota cools the ocean. The corresponding reduction in the oceanic heat content of the BIOABS ocean will eventually lead to SSTs (and hence surface heat fluxes) of experiment BIOABS approaching those of experiment PHYSABS until a new steady state with lower oceanic heat content is reached. The initial phase of this adjustment process is illustrated by results from a 20 -year integration of both models, which shows a slow decrease of the differences in air-sea heat fluxes between the two models (Figure 5). Clearly, this simulation covers only the initial phase of this several-centuries-long adjustment process which cannot presently be simulated to full extent by an eddy-permitting circulation model.

\section{Implications}

\subsection{Net Air-Sea Heat Flux}

[18] Previous studies investigating the net impact of the marine biota on the net air-sea heat flux have mainly focused on biotic impacts on the sea surface albedo. A prominent example of biotically induced changes in the albedo are calcium carbonate shells of coccolithophores that scatter, but do not absorb, light and, upon a bloom, can produce "white waters" with local albedos as much as twice as large as for clear ocean water (about 0.06, depending on solar zenith angle, atmospheric transmittance, and sea state [Ohlmann et al., 2000]). Using satellite data to globally average the effect of these local and intermittent blooms, Tyrrell et al. [1999] estimated a maximum effect of coccolithophores on the planetary albedo of 0.0013 , corresponding to a global cooling of $0.2 \mathrm{~W} \mathrm{~m}^{-2}$. Local albedo effects of phytoplankton, which both scatter and absorb short-wave radiation, are more than an order of magnitude smaller than those of coccolithophore blooms, but are more ubiquitous and thus may have a similar impact on the global scale with a slightly increased albedo [Morel and Antoine, 1994; Ohlmann et al., 2000], though, for a calculation restricted to the visible light, Frouin and Iacobellis [2002] actually report a slight reduction of the albedo in the presence of chlorophyll. Disregarding possible effects due to biotically generated surfactants, the presence of the upper ocean biota seems to reduce the total amount of short-wave radiation entering the ocean by about $0.2-0.4 \mathrm{~W} \mathrm{~m}^{-2}$. This corresponds to a cooling of the ocean and, because much of the short-wave radiation will be reflected back into space, of the planet Earth.

[19] In the present study, albedo effects are disregarded and the short-wave solar radiation entering the ocean is kept fixed for all model experiments. Only the biotically induced
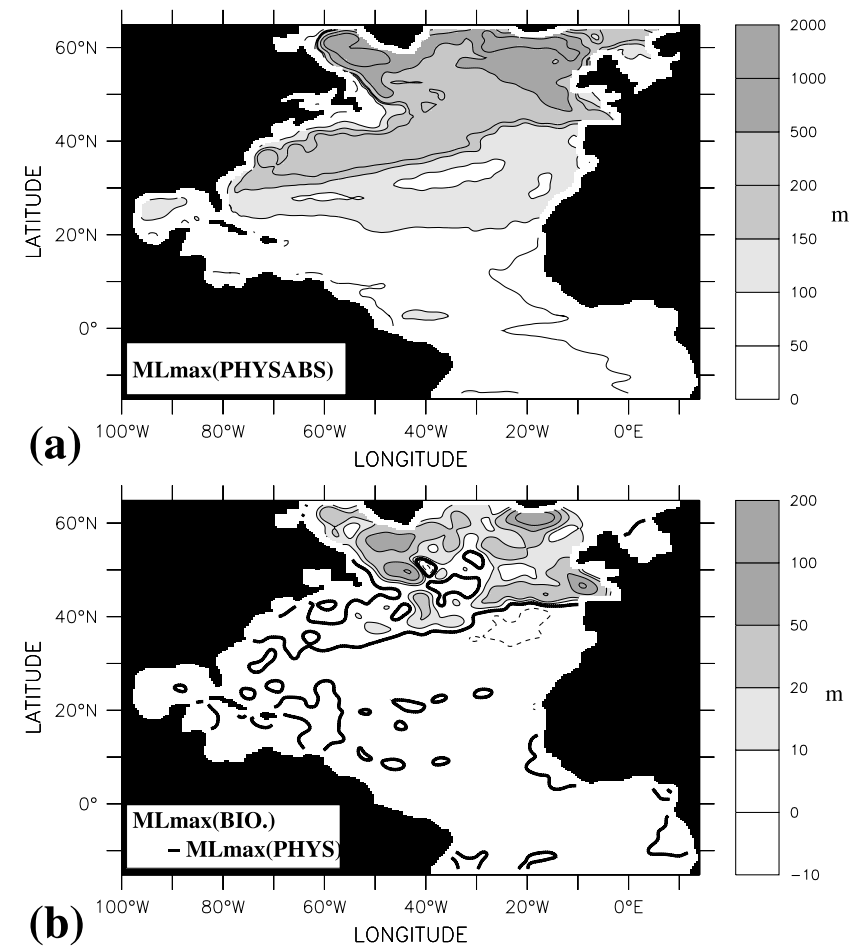

Figure 6. (a) Winter mixed-layer depth as simulated by experiment PHYSABS. (b) Simulated difference in the winter mixed-layer depth of experiment BIOABS minus experiment PHYSABS. Mixed-layer depth is defined by a density criterion of $\Delta \sigma_{0}=0.01 \mathrm{~kg} \mathrm{~m}^{-3}$. The thick line is the zero contour, and dashed lines refer to negative values. 

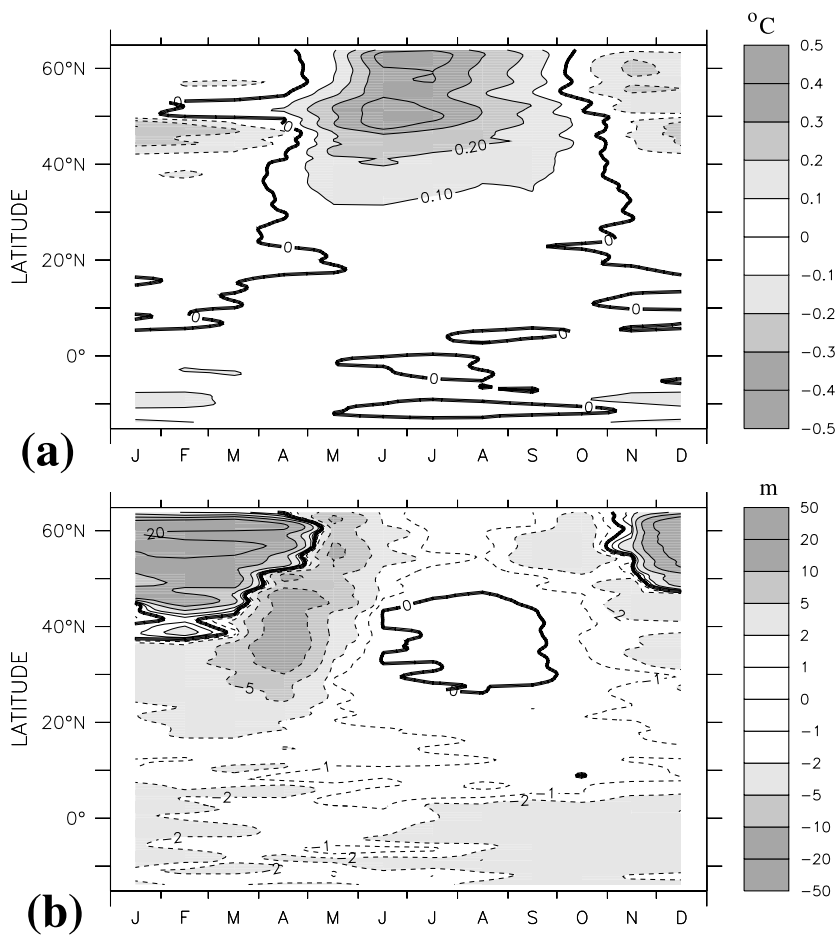

Figure 7. (a) Mean annual cycle of the difference in simulated surface temperature (experiment BIOABS minus PHYSABS) zonally averaged over the model domain. (b) Mean annual cycle of the difference in simulated mixed-layer depth (experiment BIOABS minus PHYSABS, $\Delta \sigma_{0}=0.01$ density criterion) zonally averaged over the model domain. The thick line is the zero contour, and dashed lines refer to negative values.

changes in the absorption profile in the water are investigated. Within the local approximation of the atmosphere's sensitivity as that of a passive heat buffer, it turns out that the presence of the marine biota leads to a net oceanic heat loss of about $1 \mathrm{~W} \mathrm{~m}^{-2}$ in this model. This is about 3 to 5 times larger than the estimated average cooling associated with biotically induced changes in the albedo discussed above [Morel and Antoine, 1994; Tyrrell et al., 1999; Ohlmann et al., 2000]. The additional heat loss limits the biotically induced SST rise over the North and equatorial Atlantic to about $0.03^{\circ} \mathrm{C}$, similar to the $0.04^{\circ} \mathrm{C}$ derived by Shell et al. [2003] from a global model with prescribed, satellite-derived attenuation coefficients. Because higher SSTs will tend to warm the overlying air masses which eventually are advected over the continents, absorption of solar radiation by marine phytoplankton does not only cool the ocean, but in addition, warms the land. Forcing an atmospheric model with such elevated SSTs, Shell et al. [2003] estimate that surface air temperatures on average increase by $0.05^{\circ} \mathrm{C}$, while the main effect is an increase in the amplitude of the seasonal cycle by $0.3^{\circ} \mathrm{C}$ globally and up to $1^{\circ} \mathrm{C}$ locally. Note that the cooling associated with a biotically induced increase in the albedo, for example, by coccolithophores [Tyrrell et al., 1999], will tend to reduce SSTs and thereby cool the land.

\subsection{Winter Mixed-Layer Depth}

[20] With respect to biotically induced changes in the maximum depth of the mixed layer reached during the annual cycle (in the following referred to as winter mixedlayer depth), two cases can be distinguished: A first case describes the situation with winter mixed layers of experiment PHYSABS being shallower than the typical light penetration depth in clear seawater (about 100-150 m). Here biotically induced near-surface heating in run BIOABS leads to cooling beneath the winter mixed-layer depth. This results in a stabilization of the permanent thermocline and a likely reduction in the depth of the winter mixed layer. This feature is reproduced by the model over much of the tropics and subtropics (Figure 6). In these regions, the mixed layer of experiment BIOABS is shallower by typically a few meters compared to experiment PHYSABS. A similar effect was reported in a model study by Rochford et al. [2001].

[21] In the opposite case, i.e., when winter mixed layers are deeper than the typical light penetration depth in clear seawater, all solar radiation is absorbed above the depth of the winter mixed layer, irrespective of the presence of biota. However, the additional surface heat loss via the response of the nonsolar heat flux to increased SSTs leads to a buoyancy loss of the mixed layer. This effect is largest during summer when SSTs are higher and surface mixed layers are shallower in experiment BIOABS (Figure 7). The buoyancy loss accumulates over the annual cycle and eventually leads to a deepening of the winter mixed layer. In the model, this occurs predominantly over the subpolar North Atlantic where simulated winter mixed layers are deeper by up to $100 \mathrm{~m}$ when absorption of solar radiation by chlorophyll is accounted for (Figure 6). This change in winter mixed-layer depths depends inherently on the sensitivity of the nonsolar heat flux components to changes in SST, i.e., on the additional heat loss when solar radiation is absorbed closer to the sea surface. Models that do not account for this feedback will not simulate this deepening of the winter mixed layer in response to biotic absorption of solar radiation.

\subsection{Circulation}

[22] For idealized scenarios, it has been demonstrated that biotically induced differential heating rates can set up

Figure 8. (a) Simulated mean near-surface temperature field of experiment PHYSABS averaged meridionally from $14^{\circ} \mathrm{N}$ to $22^{\circ} \mathrm{N}$. The solid line with circles refers to the maximum depth of the mixed layer $\left(\Delta \sigma=0.01 \mathrm{~kg} \mathrm{~m}^{-3}\right.$ density criterium), and arrows indicate the mean circulation in the xz plane (scaled by the aspect ratio of the figure). (b) Simulated near-surface temperature difference of experiment BIOABS minus experiment PHYSABS for the same region. Contour labels are in degrees Celsius. Superimposed are the maximum depths of the mixed layers for experiment PHYSABS (solid line with circles) and BIOABS (solid line with squares). (c) Vectors of the velocity difference (BIOABS minus PHYSABS) in the xz plane. Velocity scale is a factor of 10 smaller than in Figure 8a. Superimposed are the maximum depths of the mixed layer for the two experiments. 

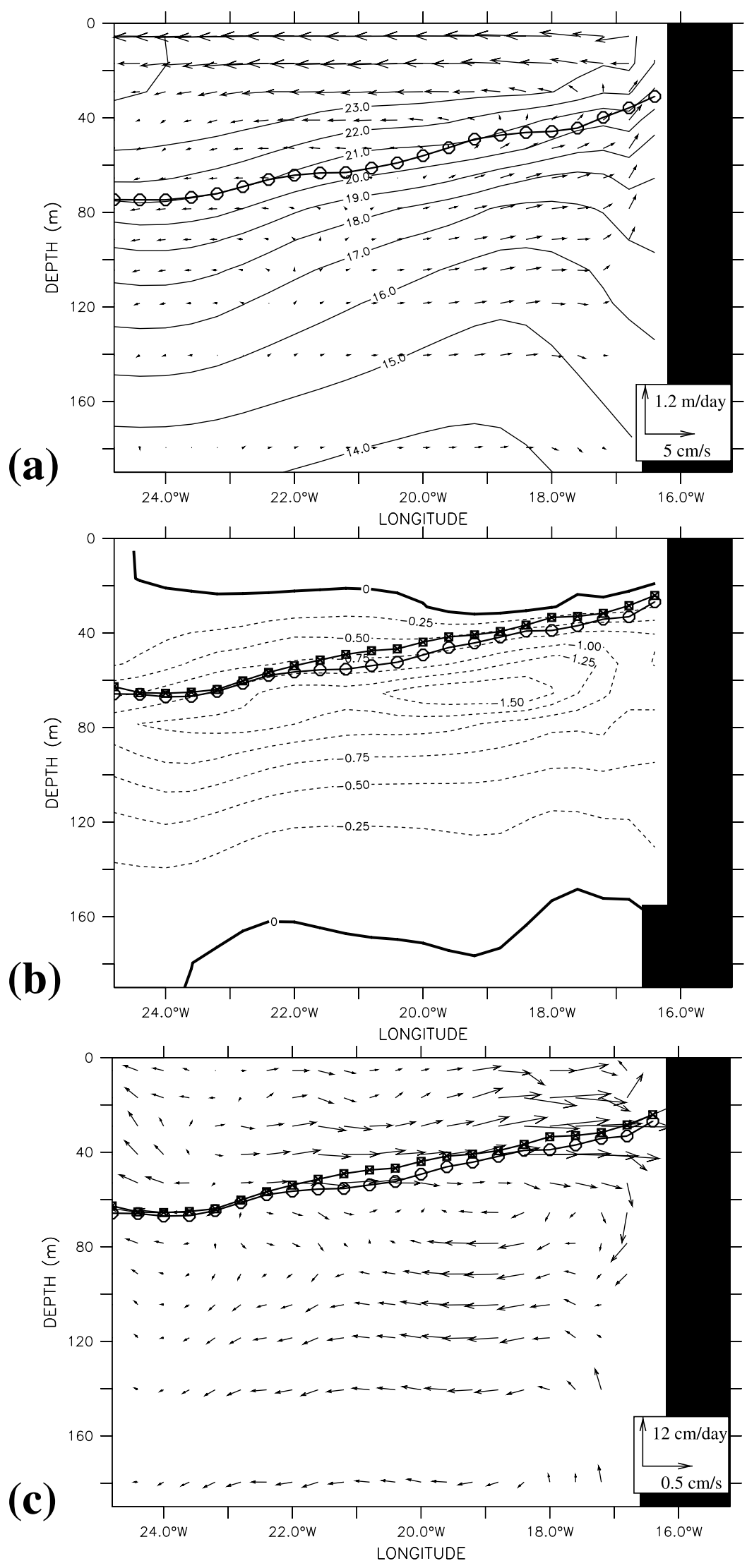

Figure 8 

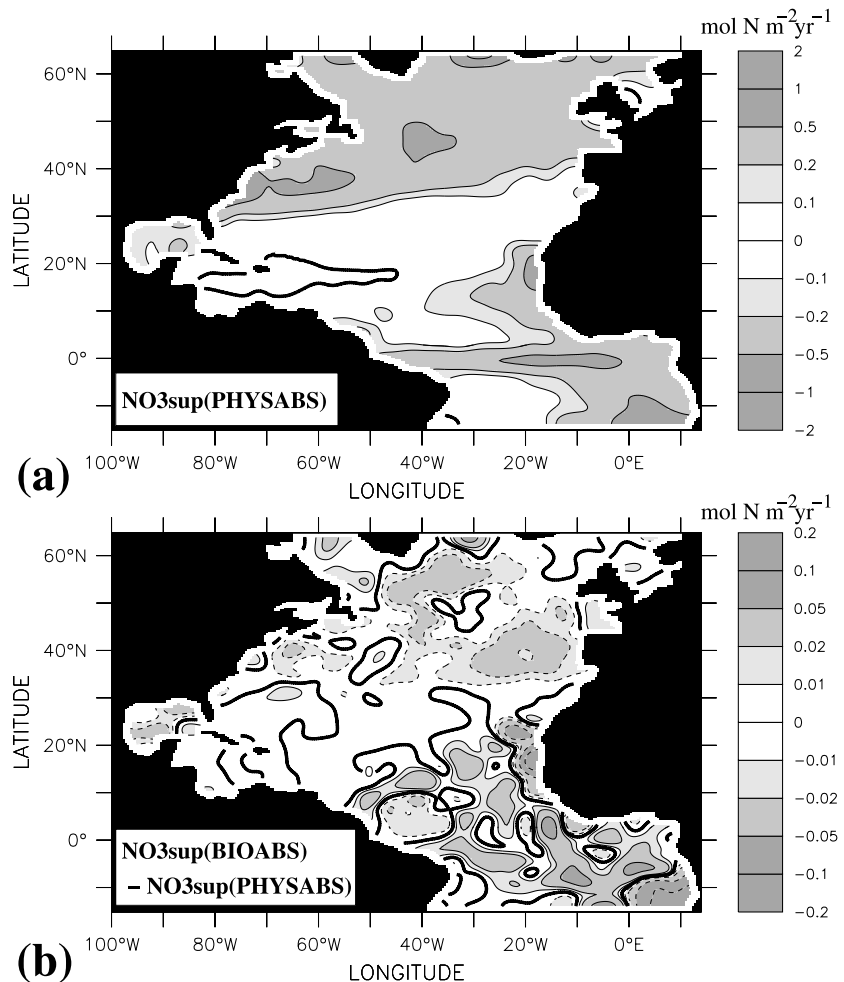

Figure 9. (a) Annual nitrate supply into the top $126 \mathrm{~m}$ as simulated by experiment PHYSABS. (b) Difference in simulated upper ocean nitrate supply of experiment BIOABS minus experiment PHYSABS. The thick line is the zero contour, and dashed lines refer to negative values.

pressure gradients and associated secondary circulations along lateral gradients in the surface chlorophyll distribution [Edwards et al., 2001]. The vertical component of this circulation may actually help to supply new nutrients and thereby feedback on the chlorophyll distribution [Edwards et al., 2004]. Although the present eddy-permitting model does not resolve the submesoscale features envisaged by Edwards et al. [2001, 2004], on a larger scale the model indeed generates a biotically effected circulation change: Along the coastal upwelling regions, for example, off West Africa, the onshore gradient in surface chlorophyll concentrations is responsible for a corresponding gradient in near-surface absorption of solar radiation (compare Figures 1 and 3). While the nonsolar heat-flux feedback limits changes in sea surface temperatures to less than $0.2^{\circ} \mathrm{C}$ (Figure 4), a pronounced biotically induced cooling by up to $1.5^{\circ} \mathrm{C}$ occurs below the mixed layer (Figure 8 ). Subsurface temperature differences are largest a few hundred kilometers offshore where water residence times are larger than in the upwelling region right off the coast. Still, the upwelled water is colder and denser in experiment BIOABS than in PHYSABS, stratification is enhanced, and more work is required to move the denser water up to the surface. The resulting changes in the zonal overturning circulation reveal a slowdown of the upwelling circulation by about $10 \%$ (Figure 8c). This response is very similar for all upwelling regions along the eastern boundary of the regional model.
[23] Note, that in contrast to biotically induced changes in the equatorial upwelling, as for example analyzed by Murtugudde et al. [2002], changes in the strength of the coastal upwelling occur in the absence of any substantial changes in the depth of the mixed layer. For this situation, and with identical wind stress fields applied to both model configurations, linear Ekman theory would not allow for any changes in the upwelling. Any changes in the upwelling circulation must therefore be the result of either nonlinear effects (e.g., via changes in the density of the upwelled water) or of some remote forcing, for the latter of which no indication was found in the present model analysis.

\subsection{Nutrient Supply, Primary Production, and Surface Chlorophyll}

[24] In the present model, which neglects nitrogen fixation and nitrogen input from land and atmosphere, nitrate supply to the euphotic zone is equivalent to new production. Since the depth of the euphotic zone differs slightly among the two experiments, a fixed depth of $126 \mathrm{~m}$ is taken as reference level instead, in order to compare nitrate supply simulated by the two model configurations.

[25] Associated with reduced coastal upwelling in run BIOABS is a reduction in nutrient supply off West Africa by as much as $0.2 \mathrm{~mol} \mathrm{~N} \mathrm{~m}^{-2} \mathrm{yr}^{-1}$ or about $10 \%$ (Figure 9). A similar reduction is found in coastal upwelling regions in the Gulf of Guinea and along the African coast south of the
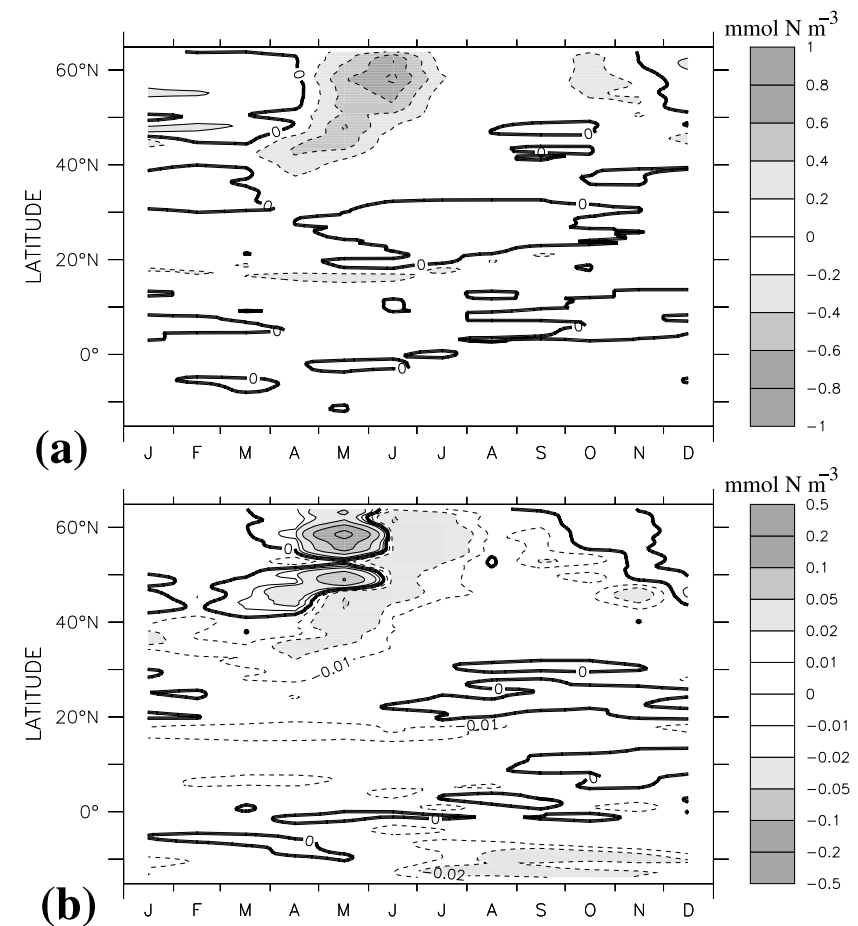

Figure 10. (a) Mean annual cycle of the difference in simulated surface nitrate (experiment BIOABS minus PHYSABS) zonally averaged over the model domain. (b) Mean annual cycle of the difference in simulated surface phytoplankton concentrations (experiment BIOABS minus PHYSABS) zonally averaged over the model domain. Units are $\mathrm{mmol} \mathrm{N} \mathrm{m}{ }^{-2}$. The thick line is the zero contour, and dashed lines refer to negative values. 


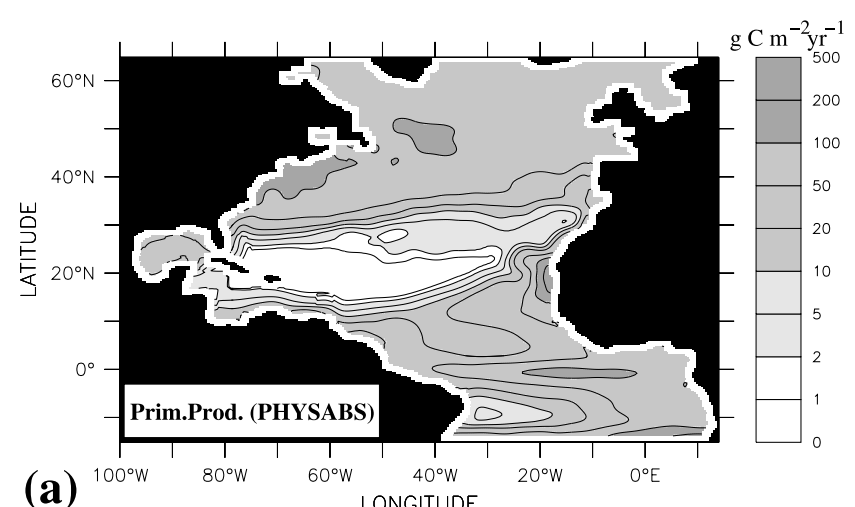

(a)

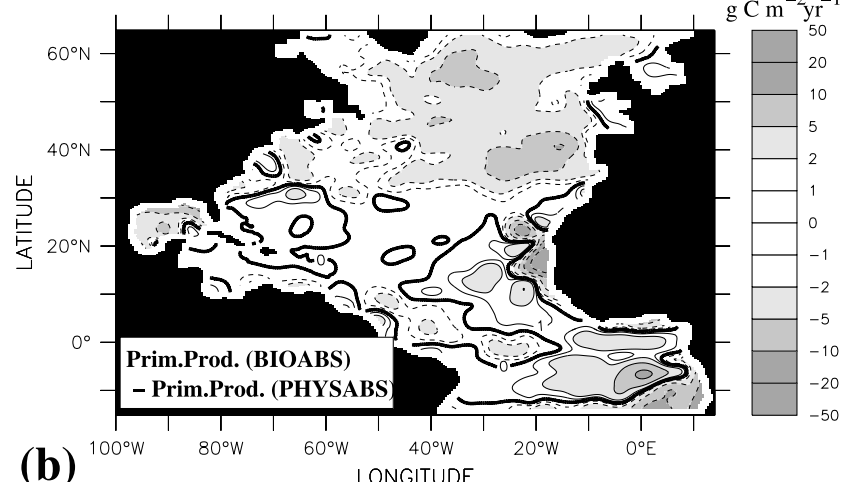

Figure 11. (a) Annual primary production simulated by experiment PHYSABS. (b) Difference in simulated primary production of experiment BIOABS minus experiment PHYSABS. Units are $\mathrm{g} \mathrm{C} \mathrm{m}^{-2} \mathrm{yr}^{-1}$. The thick line is the zero contour, and dashed lines refer to negative values.

equator. Enhanced nutrient supply is simulated farther offshore in the tropics.

[26] Unexpected at first sight is the reduction in simulated nutrient supply north of about $40^{\circ} \mathrm{N}$, where winter mixed layers turn out to be generally deeper when biotically induced absorption of solar radiation is accounted for (Figure 6). In this region, nitrate concentrations in the winter mixed layer simulated by experiment BIOABS are indeed slightly higher (by $0.1 \mathrm{mmol} \mathrm{m}^{-3}$ on average) than those of run PHYSABS (Figure 10). Surface nitrate concentrations are, however, lower in experiment BIOABS right after the spring bloom and throughout summer. These lower concentrations are the result of a more rapid development of the spring bloom because of a more rapid shoaling of the surface mixed layer and associated improvement of light conditions in experiment BIOABS. As a result, spring-bloom phytoplankton concentrations are higher and indicate that during this time of the year, there is a positive feedback; that is, absorption by chlorophyll leads to increased chlorophyll levels in the model.

[27] Lower surface nitrate concentrations during spring and summer of experiment BIOABS, together with lower phytoplankton concentrations after the spring bloom, also reflect reduced diffusive nitrate supply across the seasonal nutricline. Biotically induced warming of the seasonal mixed layer and cooling underneath leads to stronger stratification and, via the stratification-sensitive turbulence closure [Gaspar et al., 1990], to lower levels of turbulent vertical mixing and associated nutrient supply. This constitutes a negative feedback and dominates biotically induced effects on the total annual nitrate supply between about $35^{\circ} \mathrm{N}$ and $60^{\circ} \mathrm{N}$. Averaged over the entire model domain, simulated nitrate supply decreases by less than $2 \%$ from $0.210 \mathrm{~mol} \mathrm{~m}^{-2} \mathrm{yr}^{-1}$ in run PHYSABS to $0.207 \mathrm{~mol} \mathrm{~m}^{-2} \mathrm{yr}^{-1}$ in run BIOABS. Although this difference is robust in each of the five model years analyzed, it is of the same magnitude as the internally generated interannual variability within the eddy-permitting model.

[28] In the present model configuration of the North Atlantic, as well as in the real ocean [Longhurst, 1998], simulated phytoplankton growth is, in low latitudes, generally limited by nutrients rather than by light. This is consistent with the finding that tropical and subtropical regions with elevated input of nutrients into the euphotic zone in experiment BIOABS also display elevated levels of simulated primary production (Figure 11). Simulated total primary production declines by more than $20 \mathrm{~g} \mathrm{C} \mathrm{m}^{-2} \mathrm{yr}^{-1}$ or approximately $10 \%$ in the upwelling regions along the west African coast, and by a smaller amount over much of the midlatitude and subpolar North Atlantic. Smaller regions that show an increase in primary production are found in the tropics. At higher latitudes, where light limitation becomes more important, the close correlation between changes in nutrient supply and primary production disappears, and primary production is smaller in experiment BIOABS essentially everywhere north of $35^{\circ} \mathrm{N}$. In particular, there is a trend for an increase in $f$ ratios when biotic radiative heating is accounted for. This is caused by the more rapid shoaling of the mixed layer in spring and the associated faster development of the spring bloom that results in a faster conversion of nutrients into sinking detritus. Overall, simulated primary production decreases by a slightly larger fraction (3\%) than the nutrient supply.

[29] The difference in the simulated surface chlorophyll field is displayed in Figure 12: Surface chlorophyll is, on average, reduced by about $3 \%$ from $0.146 \mathrm{mg} \mathrm{m}^{-3}$ to

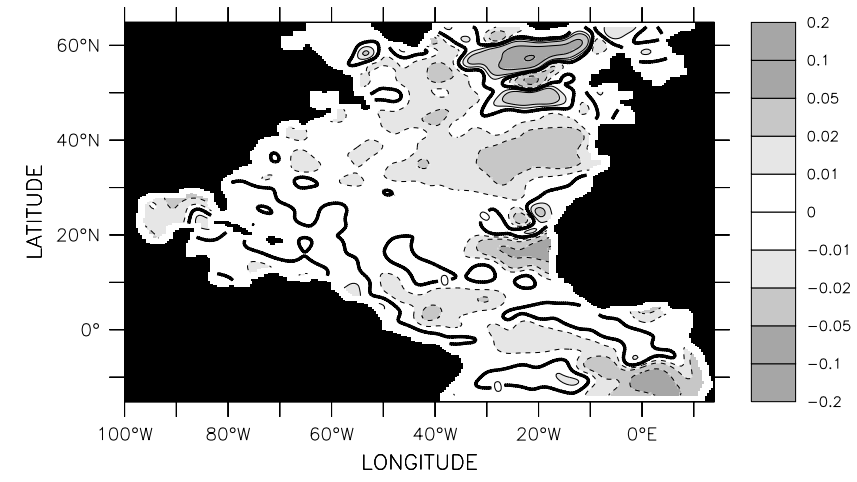

Figure 12. Simulated difference in annual-mean surface chlorophyll concentrations of experiment BIOABS minus experiment PHYSABS. Regions with a positive difference exhibit a positive feedback of biotically induced radiative heating on chlorophyll, while the feedback is negative

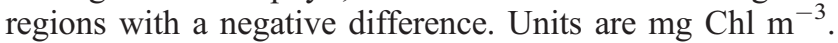
The thick line is the zero contour, and dashed lines refer to negative values. 

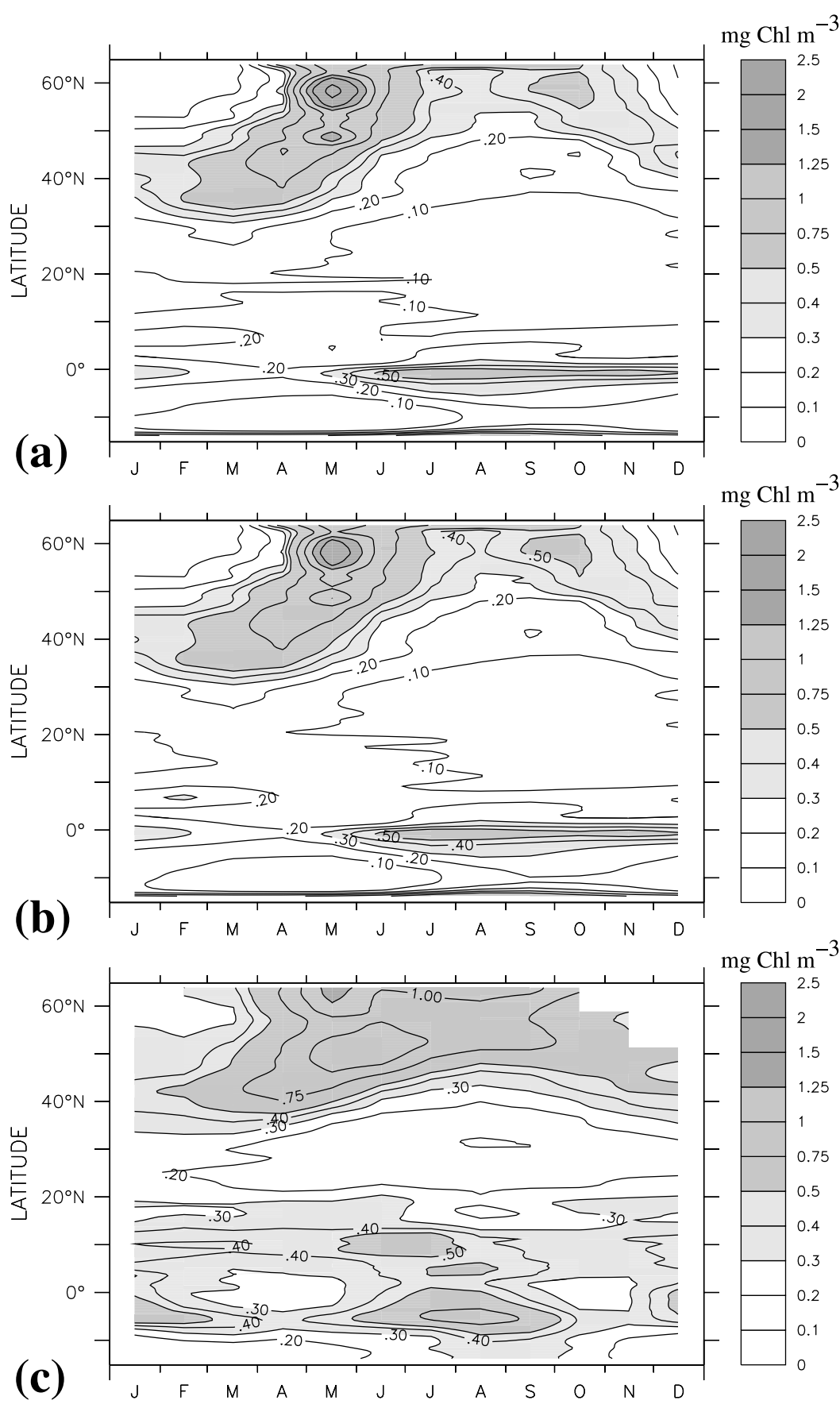

Figure 13. Seasonal cycle of zonally averaged surface chlorophyll as (a) simulated by experiment BIOABS, (b) simulated by experiment PHYSABS, and (c) observed by the SeaWiFS satellite instrument for the period 1998-2002. Units are $\mathrm{mg} \mathrm{Chl} \mathrm{m}{ }^{-3}$.

$0.141 \mathrm{mg} \mathrm{m}^{-3}$, again with largest absolute reductions in the upwelling regions along the west African coast. In the subpolar North Atlantic, there are, however, regions with a local increase in simulated chlorophyll when biotically induced radiative heating is accounted for. These regions display a pronounced spring bloom, and peak phytoplankton concentrations increase by more than $30 \%$ in experiment BIOABS. In some locations, the more rapid shoaling of the mixed layer, combined with ecosystem model parameters tuned for the PHYSABS setup, results in unrealistically high surface chlorophyll concentrations of more than $12 \mathrm{mg} \mathrm{Chl} \mathrm{m}^{-3}$ at the peak of the bloom. Enhanced chlorophyll concentrations during the spring bloom are also evident in the zonal average (Figure 13). Note that the SeaWiFS data indicate a less intense spring bloom and higher chlorophyll concentrations during summer (Figure 13c). This systematic overestimate of spring bloom concentrations simulated by the present ecosystem model tends to be larger in the BIOABS run. However, the differences among the two model results are generally small compared to the deviation of either model from the SeaWiFS data. 
[30] Interestingly, even those subpolar regions that show an increase in mean surface chlorophyll concentrations do not display an increase in annual-mean nutrient supply or primary production (Figures 9 and 11). This indicates that even in the relatively simple NPZD model used here, there is no simple relationship between surface chlorophyll and depth-integrated primary production.

\section{Conclusions}

[31] The inclusion of biotically induced radiative heating in the model results in an average cooling of the ocean by about $1 \mathrm{~W} \mathrm{~m}^{-2}$. It leads to generally shallower mixed layers in summer and, in middle and high latitudes, to a deepening of the winter mixed layer by maximum values of more than $100 \mathrm{~m}$. Nutrient supply to the euphotic zone and primary production shows an overall decrease by a few percent, with largest changes located in the coastal upwelling regions off West Africa. Simulated surface chlorophyll concentrations decrease almost everywhere over the model domain; that is, the feedback of biotically induced radiative heating on the chlorophyll concentration is generally negative. An exception is parts of the subpolar North Atlantic where annual mean chlorophyll concentrations increase as a result of an intensification of the spring bloom.

[32] Having demonstrated that within the approximations of the present model, marine phytoplankton cools the ocean and, via higher SSTs, warms the land, it may be questioned whether such effects have to be included in models used to attempt predicting the future climate evolution. While the net cooling of the ocean amounts to $1 \mathrm{~W} \mathrm{~m}^{-2}$, which is of similar magnitude as the present anthropogenic contribution to the greenhouse effect, possible feedback processes can apparently change surface chlorophyll concentrations by only a few percent. Admittedly, this result is based on a very simple NPZD-type ecosystem model and will have to be tested against future studies using more realistic descriptions of the marine ecosystem that, for example, can allow for changes in species composition.

[33] A probably more critical assumption of the present study is the treatment of the atmosphere as a passive heat buffer. This local approximation of the nonsolar heat-flux response to elevated SSTs is generally assumed valid for extratropical SST anomalies of scales small compared to the atmospheric Rossby radius $\left(\sim 10^{3} \mathrm{~km}\right)$. On larger scales, which may for example be reached during a basin-scale spring bloom, this method will tend to overestimate the heat flux sensitivity to SST changes [Rahmstorf and Willebrand, 1995]. Particularly in the tropics, the intimate coupling of ocean and atmosphere can furthermore be expected to generate a nonlinear response including SST-driven changes in the wind field, in cloudiness, or in precipitation [Gildor et al., 2003]. To fully investigate such feedbacks, coupled atmosphere-ocean models with interactive marine biology will be needed. Using a highly simplified coupled model, Timmerman and Jin [2002] already found that the presence of phytoplankton can indeed affect the amplitude and the asymmetry of the El Niño Southern Oscillation. It remains to be investigated whether feedbacks involving an active atmosphere exist also outside the tropics. For the time being, it can be concluded that the feedback of radiative heating on the surface chlorophyll concentration is probably small $\left(\sim 0.03 \mathrm{~W} \mathrm{~m}^{-2}\right)$ and negative. This is negligible to the much larger $\left(\sim 1.0 \mathrm{~W} \mathrm{~m}^{-2}\right)$ total impact of marine phytoplankton on the upper-ocean heat budget and the SST, which is not yet taken into account in most current climate models used to address possible consequences of a similarly large surface heat-flux forcing by anthropogenic $\mathrm{CO}_{2}$ emissions.

[34] Acknowledgment. I thank the two reviewers for their constructive comments that helped to improve the manuscript.

\section{References}

Barnier, B., L. Siefridt, and P. Marchesiello (1995), Surface thermal boundary condition for a global ocean circulation model from a three-year climatology of ECMWF analyses, J. Mar. Syst., 6, 363-380.

Edwards, A., T. Platt, and D. G. Wright (2001), Biologically induced circulation at fronts, J. Geophys. Res., 106, 7081-7095.

Edwards, A. M., D. G. Wright, and T. Platt (2004), Biological heating effect of a band of phytoplankton, J. Mar. Syst., 49, 89-103.

Frouin, R., and S. F. Iacobellis (2002), Influence of phytoplankton on the global radiation budget, J. Geophys. Res., 107(D19), 4377, doi:10.1029/ 2001JD000562.

Gaspar, P., Y. Gregoris, and J.-M. Lefevre (1990), A simple eddy kinetic energy model for simulations of the oceanic vertical mixing: Tests at station Papa and Long-Term Upper Ocean Study site, J. Geophys. Res., $95,16,179-16,193$.

Geider, R. J., H. L. MacIntyre, and T. M. Kana (1996), A dynamic model of photoadaptation in phytoplankton, Limnol. Oceanogr., 41, 1-15.

Geider, R. J., H. L. MacIntyre, and T. M. Kana (1998), A dynamic regulatory model of phytoplanktonic acclimation to light, nutrients, and temperature, Limnol. Oceanogr., 43, 679-694.

Gibson, J. K., P. Kallberg, S. Uppala, A. Hernandez, A. Nomura, and E. Serrano (1997), ECMWF Re-Analysis Project report series: 1. ERA description, report, 72 pp., Eur. Cent. for Medium-Range Weather Forecast., Reading, UK.

Gildor, H., A. H. Sobel, M. A. Cane, and R. N. Sambrotto (2003), A role for ocean biota in tropical intraseasonal atmospheric variability, Geophys. Res. Lett., 30(9), 1460, doi:10.1029/2002GL016759.

Haney, R. L. (1971), Surface thermal boundary condition for ocean circulation models, J. Phys. Oceanogr., 1, 241-248.

Jerlov, N. G. (1976), Marine Optics, 231 pp., Elsevier, New York.

Ledwell, J. R., A. J. Watson, and C. S. Law (1993), Evidence for slow mixing across the pycnocline from an open-ocean tracer-release experiment, Nature, 364, 701-703.

Ledwell, J. R., A. J. Watson, and C. S. Law (1998), Mixing of a tracer in the pycnocline, J. Geophys. Res., 103, 21,499-21,529.

Levitus, S., R. Burgett, and T. P. Boyer (1994), World Ocean Atlas 1994, vol. 3, Salinity, NOAA Atlas NESDIS 3, 99 pp., Natl. Oceanic and Atmos. Admin., Silver Spring, Md.

Longhurst, A. (1998), Ecological Geography of the Sea, 398 pp., Academic, San Diego, Calif.

Martin, P. J. (1985), Simulation of mixed layer at OWS November and Papa with several models, J. Geophys. Res., 90, 903-916.

Morel, A. (1988), Optical modeling of the upper ocean in relation to its biogenous matter content (Case I waters), J. Geophys. Res., 93, 10,74910,768 .

Morel, A., and D. Antoine (1994), Heating rate within the upper ocean in relation to its bio-optical state, J. Phys. Oceanogr., 24, 1652-1665.

Murtugudde, R., J. Beauchamp, C. R. McCLain, M. Lewis, and A. J. Busalacchi (2002), Effects of penetrative radiation on the upper tropical ocean circulation, J. Clim., 15, 470-486.

Ohlmann, J. C., D. A. Siegel, and C. D. Mobley (2000), Ocean radiant heating: I. Optical influences, J. Phys. Oceanogr., 30, 1833-1848.

Oschlies, A. (2002), Nutrient supply to the surface waters of the North Atlantic: A model study, J. Geophys. Res., 107(C5), 3046, doi:10.1029/2000JC000275

Oschlies, A., and V. Garçon (1999), An eddy-permitting coupled physicalbiological model of the North Atlantic: 1. Sensitivity to advection numerics and mixed layer physics, Global Biogeochem. Cycles, 13, $135-160$.

Oschlies, A., W. Koeve, and V. Garcon (2000), An eddy-permitting coupled physical-biological model of the North Atlantic: II. Ecosystem dynamics and comparison with satellite and JGOFS local studies data, Global Biogeochem. Cycles, 14, 499-523.

Pacanowski, R., K. Dixon, and A. Rosati (1991), The G.F.D.L Modular Ocean Model users guide version 1, Tech. Rep. 2, GFDL Ocean Group, Geophys. Fluid Dyn. Lab., Princeton, N. J. 
Rahmstorf, S., and J. Willebrand (1995), The role of temperature feedback in stabilizing the thermohaline circulation, J. Phys. Oceanogr., 25, $787-$ 805

Reynolds, R. W., and T. M. Smith (1994), Improved global sea surface temperature analysis using optimum interpolation, J. Clim., 7, 929948.

Rochford, P. A., A. B. Kara, A. J. Wallcraft, and R. A. Arnone (2001) Importance of solar subsurface heating in ocean general circulation models, J. Geophys. Res., 106, 30,923-30,938.

Sathyendranath, S., A. D. Gouveia, S. R. Shetye, P. Ravindran, and T. Plat (1991), Biological control of surface temperature in the Arabian Sea, Nature, 349, 54-56.

Shell, K. M., R. Frouin, S. Nakamoto, and R. C. J. Sommerville (2003), Atmospheric response to solar radiation absorbed by phytoplankton, J. Geophys. Res., 108(D15), 4445, doi:10.1029/2003JD003440.
Simonot, J.-Y., E. Dollinger, and H. LeTreut (1988), Thermodynamicbiological-optical coupling in the oceanic mixed layer, J. Geophys. Res., 93, 8193-8202.

Simpson, J. J., and T. D. Dickey (1981), The relationship between downward irradiance and upper ocean structure, J. Phys. Oceanogr., 11, 309323.

Timmermann, A., and F.-F. Jin (2002), Phytoplankton influences on tropical climate, Geophys. Res. Lett., 29(23), 2104, doi:10.1029/2002GL015434. Tyrrell, T., P. M. Holligan, and C. D. Mobley (1999), Optical impacts of oceanic coccolithophore blooms, J. Geophys. Res., 104, 3223-3241.

A. Oschlies, School of Ocean and Earth Science, Southampton Oceanography Centre, European Way, Southampton SO14 3ZH, UK. (andreas.oschlies@soc.soton.ac.uk) 